\title{
doispontos:
}

\section{¿Voluntad o razón en el origen del orden político? La respuesta de la teología política medieval y contemporánea.}

\author{
Will or reason in the origin of the political order? The answer of Medieval and \\ Contemporary Political Theology.
}

Francisco Bertelloni

Universidad de Buenos Aires - UBA

fbertelloni@sinectis.com.ar

Resumen: La pregunta planteada en el título de este trabajo reitera una alternativa que se ha transformado en un locus classicus de la teoría política: ¿el orden político forma parte de la constitución racional de la realidad y, por ello, no necesita ser creado pues basta con descubrir su existencia como una entidad más entre los entes de la naturaleza? ¿O ese orden político solo existe cuando es instituido por el hombre y, por ello, es el resultado de un acto de la voluntad humana? No analizaré aquí cada una de esas dos posiciones, naturalista la primera y voluntarista la segunda, sino que intentaré mostrar cuál fue la respuesta de la teología política de Egidio Romano y de Carl Schmitt a la pregunta por el origen del Estado.

Palabras llave: naturalismo, voluntarismo, teoría política, teología política, Egidio Romano, Carl Schmitt, origen del Estado.

Resumo: A pergunta proposta no título deste trabalho reitera uma alternativa que se transformou num locus classicus da teoria política: a ordem política toma parte na constituição racional da realidade e, assim, não precisa ser criada na medida em que sua existência é suficientemente descoberta como uma entidade dentre os demais entes da natureza ou tal ordem política apenas existe quando instituída pelo homem e, assim, é o resultado de um ato da vontade humana? Não vou analisar aqui cada uma dessas duas posições, a primeira naturalista, e a segunda voluntarista, mas buscarei mostrar qual foi a resposta da teologia política de Egídio Romano e de Carl Schimitt para a pergunta sobre a origem do Estado.

Palavras-chave: naturalismo, voluntarismo, teoria política, teologia política, Egídio Romano, Carl Schmitt, origem do Estado.

Abstract: The question at the title of this paper, "Will or reason in the origin of the political order? The answer of Medieval and Contemporary Political Theology", renews an alternative that has become a locus classicus of political theory: the political order enters in the rational constitution of reality and, consequently, is not a created thing but has its existence discovered as an entity amongst other natural entities, or, on the other hand, the political order dues its existence exclusively to human institution and, consequently, appears as a result of an act of human will? I will not although analyze here both positions, one naturalist and another voluntarist, but I intend to show how the political theories of Gilles of Rome and Carl Schmitt answer the question about the Origin of the State.

Keywords: naturalism, voluntarism, political theory, political theology, Gilles of Rome, Carl Schmitt, origin of the State. 


\section{Introducción}

La pregunta que plantea el título de mi trabajo reitera una alternativa que hoy es ya un locus classicus de la teoría política: ¿el orden político forma parte de la constitución de la realidad y, por ello, no es creado o instituido por el hombre, sino que basta con descubrir su existencia como una entidad existente en la naturaleza? ¿O bien el orden político existe solo porque es instituido por la voluntad y el arbitrio humanos? El lector conoce las respuestas históricas a esas preguntas y sabe que, aunque es posible encontrar posiciones menos definidas desde el punto de vista teórico y cronológico, con todo, en los momentos más importantes de la filosofía política griega predominó la tesis que afirma que el orden político es una entidad natural, mientras que la tesis que lo entiende como construcción artificial derivada de la voluntad humana predominó en la teoría política moderna. No analizaré aquí esas posiciones. Sólo intentaré responder una pregunta hasta hoy poco planteada y que puede formularse así: ¿de qué modo naturalismo y voluntarismo se encuentran implicados en la respuesta de la teología política al problema del origen del orden político? Responder esta pregunta exige precisar, primero, qué significa teología política.

En sentido amplio es teología política toda teoría política en cuyo desarrollo la teología está más o menos comprometida. En un libro reciente M. Scattola reconstruyó la génesis histórica de esta teología política en sentido amplio y mostró que ella existía ya en el Imperio Romano Cristiano a partir de Constantino, luego en S. Agustín y en el medioevo, cuando numerosos escritos eclesiológico-políticos, que la historiografía alemana llamó kirchenpolitische Schriften, intentaron definir las jurisdicciones de los poderes temporal y espiritual. Scattola muestra también que en la modernidad, hasta hoy, la teología, por aceptación o por rechazo, ha influido de algún modo en la formación de gran parte del pensamiento político ${ }^{1}$.

Pero la teología política que tomaré aquí como tema es la politische Theologie, i.e. la teología política en sentido estricto, cuyo indiscutido creador fue el jurista alemán C. Schmitt. ¿Cómo se diferencia esta nueva politische Theologie de la teología política medieval? Para reconstruir el desarrollo histórico de las ideas políticas medievales la historiografía tomó como modelo el Estado secular moderno. Quizá el mejor paradigma de esa reconstrucción fue la obra de G. de Lagarde, La naissance de l'esprit laïque au déclin du moyen âge ${ }^{2}$. El atractivo título de esta obra estimuló a la historiografía de la teoría política hacia la búsqueda en el medioevo de los primeros signos del Estado secular, construido por la razón o accesible a ella, y definido por su independencia respecto de la teología y de la revelación. Como resultado de esa búsqueda la historia de las teorías políticas medievales fue leída como una evolución desde la teología política medieval, predominante en la alta edad media, hacia la racionalidad del Estado laico y del pensamiento político secular que la historiografía encontró en la baja edad media ${ }^{3}$.

Pero a pesar del éxito de esta historiografía que, en su búsqueda del Estado laico, intentaba superar la teología política medieval, una nueva teología política - la politische Theologie de Schmitt -, muy diferente de la medieval, logró introducirse en el pensamiento político postmedieval. Su presencia dentro del pensamiento político laico y secular moderno sería una contradicción si ella tuviera las mismas características que la teología política medieval. Pero la politische Theologie no es contradictoria con el pensamiento político moderno, pues ella no se presenta como alternativa frente a la filosofía política secular o como opuesta a

\footnotetext{
${ }^{1}$ Merio Scattola, Teología política, Nueva Visión, Bs. As., 2008.

${ }^{2}$ Georges de Lagarde, La naissance de l'esprit lä̈que au déclin du moyen âge. T. I: Bilan du XIII siècle. T. II: Marsile de Padoue ou le premier théoricien de l'État laïque, Saint-Paul-Trois-Châteaux, éditions Béatrice, 1934, con sucesivas reediciones.

${ }^{3}$ Esta actitud ha sido tipificada por historiadores como "colonización" del pasado. Acerca de la conducta historiográfica “colonizadora” v. Gregorio Piaia, "Storia della filosofia e decolonizzazione del passato”, en Id., Il lavoro storico-filosofico. Questioni di metodo ed esiti didattici, Padova, 2007, pp. 11-30 (originalmente publicado en Storiografia ed ermeneutica. Atti del XIX Convegno di assistenti universitari di filosofia, Padova, Gregoriana, 1974, pp. 47-60. Más recientemente v. Mariano Pérez Carrasco, "El giro hacia la descolonización del pasado en la historiografía medieval” en Patristica et Mediaevalia XXXVII (2016), pp. 37-50.
} 
ella. La politische Theologie tampoco descansa en el télos de una ética cristiana que identifica el fin último del hombre con su plena realización en la vida futura, i.e. ella no coloca en la base de su autoconstrucción como teoría política a la soteriología, que fue el nutriente básico de la teología política medieval. En cambio, para construirse como teoría política, la politische Theologie asumió una opción teórica absolutamente novedosa. Esa opción fueron las estructuras formales de algunos temas de la teología medieval. Al momento de identificar la más importante de todas esas estructuras formales, la politische Theologie eligió el milagro como pilar básico de su construcción, y estereotipó el milagro como momento de plena manifestación de la omnipotencia divina. Pues cuando Dios opera en la realidad mediante la ley natural, actúa respetando la vigencia de esta causalidad natural que opera como mediadora entre Él y la realidad. Mientras que cuando Él opera un milagro, pasa por encima de las causas naturales y actúa directamente sobre la realidad, y por ello aparece como más poderoso, pues en este caso se muestra como ab-solutus, i.e. opera sobre la realidad sin intermediarios y no obligado por sus propias leyes. Puesto que Dios manifiesta toda su potencia en el milagro, éste ofrece todos los elementos para presentarse como el momento más emblemático de la teología.

La politische Theologie schmittiana se apropió del milagro, lo despojó de su contenido carismático, formalizó sus estructuras, y las utilizó para explicar el fenómeno de la politicidad perdida y confundida con el orden jurídico-normativo. De ese modo Schmitt transformó el milagro en la categoría por excelencia para llegar a lo que él considera el tema central de su teoría política: la identificación del soberano como instancia de indiscutida politicidad. De este procedimiento resultó una fórmula exitosa que expresa una situación política estructuralmente paralela a la situación milagrosa de la teología: soberano es el que decide sobre el estado de excepción ${ }^{4}$. Del mismo modo como en el milagro Dios suspende la vigencia de las leyes naturales para operar directamente con su poder absoluto, así el soberano suspende la vigencia del orden normativo, declara esa vigencia de las normas en estado de excepción y opera directamente sobre la realidad, sin normas, pero para crear nuevas normas.

Aquíl limito mi uso de la expresión teología política a este significado schmittiano, i.e. a la teología política en sentido estricto, a la politische Theologie. ¿Cuál fue la respuesta de esta teología política al problema del origen del orden político? Para responderla, expondré primero la teología política de Egidio Romano en su tratado De ecclesiastica potestate, que es el paradigma mejor logrado de teología política anterior a Schmitt. Luego presento una síntesis de la politische Theologie de Schmitt. Mi objetivo es mostrar el modo como estas dos formas de teología política responden la pregunta: ¿voluntarismo o naturalismo en el origen del orden político?

\section{La plenitudo potestatis papal según la teología política de Egidio Romano}

Ya mucho antes de Schmitt, el milagro entendido como introducción en la realidad de un nuevo tipo de causalidad, no natural, había sido un tema central de la teología, de la filosofía y de la teoría política medievales. Curiosamente fue Egidio Romano, discípulo de Tomás de Aquino en París entre 1268 y 1272, quien hacia 1302, en su tratado De ecclesiatica potestate ${ }^{5}$, dejó de lado las doctrinas políticas naturalistas de su maestro y anticipó un esquema similar al que utiliza la contemporánea politische Theologie para formular, en términos filosóficos, una teoría del poder total del Papa, soberano absoluto cuya relevancia ha caído en el olvido de la teoría política posterior. Para Egidio no vale el naturalismo de Tomás de Aquino que fundamenta la política en una ley natural teleológica, ni la soberanía papal está asociada a la causalidad natural o a las leyes regulares de la naturaleza, sino que solo surge en el ámbito de la sobrenaturaleza y de la historia de la salvación. Su fisonomía es la de una causalidad absolutamente excepcional en relación con las leyes naturales. Esa causalidad excepcional es la de la plenitud del poder divino y ella se manifiesta cuando

\footnotetext{
${ }^{4}$ Carl Schmitt, Politische Theologie. Vier Kapitel zur Lehre von der Souveränität, Duncker \& Humblot, Műnchen-Leipzig, ${ }^{2} 1934$, p.11.

${ }^{5}$ En adelante cito página de la edición de R. Scholz, Aegidius Romanus. De ecclesiastica potestate, Scientia, Aalen, 1961.
} 
Dios introduce su omnipotencia en el mundo natural, neutraliza las leyes naturales y, o bien produce, sin ellas, todo y lo mismo que puede producir con ellas, o produce, con su omnipotencia, efectos que el orden de las causas naturales nunca podría producir. Análogamente, y contra la naciente filosofía política que asociaba la política en la natura, Egidio ancla la política en el orden sobrenatural resultante de la historia de la salvación cristiana y en la plenitudo potestatis papal que opera sobre la Ecclesia con un poder absoluto análogo al poder absoluto con el que Dios opera sobre el mundo. De este esquema teológico aplicado al orden político resultó una teologización total de la política.

Esa contraposición generó dos tipologías de la política radicalmente diferentes. Una, el naturalismo político medieval, apoyado en la regularidad y frecuencia de la legalidad del orden natural. Esta legalidad permitía atribuir al naturalismo político una buena dosis de racionalidad, pues regularidad y frecuencia actuaban como categorías conceptuales básicas de su arquitectura teórica. Otra, la teología política medieval, para la cual el orden político no se apoya en la naturaleza, sino que depende de la decisión de un poder absoluto equivalente a un primero después de Dios, pero en la tierra: el sacerdocio. Egidio construye un orden político piramidal cuyo vértice lo ocupa el primer sacerdote, el Papa. Éste, como supremo administrador de los medios de salvación, posee una potestas coactiva ilimitada (plenitudo potestatis), cuyas características son tres: es ejercida por el Papa dentro de una Ecclesia que abarca toda la realidad, espiritual $y$ temporal; alcanza a todos los cristianos dentro de esa Ecclesia, clérigos y laicos; y es condición de la salus, i.e. de la realización de los hombres sobre los cuales es ejercida la potestas papal. De allí su conclusión: extra Ecclesiam nulla salus, i.e. fuera del ordo y la legalidad eclesiásticos y sin subjectio a la potestas papal el hombre se destruye y perece. Con ello, el Arca de Noé, imagen veterotestamentaria del único espacio posible de preservación de las especies, se transformaba en la prefiguración emblemática de la Ecclesia neotestamentaria como único espacio de realización humana.

La síntesis precedente se apoya en tres elementos: un poder absoluto, un orden eclesiástico/sobrenatural instituido y sostenido por ese poder absoluto, y la posibilidad del hombre de no perecer y de realizarse gracias a ese orden eclesiástico. Nótese que en esta argumentación el punto de partida introducido como axioma y primera certeza es el dato revelado transmitido por Mateo 16, 19: la existencia del poder de Pedro como sede de todo el poder, espiritual y temporal. La segunda certeza tampoco se demuestra, sino que la ofrece la experiencia; ésta constata que, además del poder absoluto, existen poderes menores, por ej., los poderes temporales. De inmediato, para establecer las relaciones entre el poder total del Papa y los poderes temporales menores, Egidio recurre a Dionisio Pseudoareopagita y muestra que en toda la realidad se verifica una reductio de lo inferior a lo superior mediante intermediarios ${ }^{6}$. Y por fin aplica esa reductio per media a las relaciones entre el poder temporal y el espiritual: el poder temporal se reduce, i.e. se subordina al espiritual, no directamente, sino mediante intermediarios. Egidio, pues, no recurre a Dionisio para fundamentar el hecho de la subordinación de reinos y naciones al poder espiritual - pues esa subordinación es axiomática y surge de Mateo, 16,19 -, sino para expresar, con conceptos filosóficos, el modo como naciones y reinos se subordinan a la Iglesia y las relaciones entre ambos derivadas de ese modo. Ese modo de subordinación, en situaciones de normalidad, muestra que el poder temporal está ordenado al espiritual como lo inferior a lo superior según la estructura de la mediación gradual.

Sin embargo, esta mediación no disminuye ni atenta contra la reductio, pues a pesar de la mediación, subsiste la subordinación total del poder temporal respecto del espiritual: gladius temporalis ... reducendus est per spiritualem tamquam per superiorem?

\footnotetext{
6“... secundum Dionysium in De Angelica Ierarchia lex divinitatis est infima in suprema per media reducere. Hoc ergo requirit ordo universi, ut infima in suprema per media reducere" (p. 12).

${ }^{7}$ Ibid., p. 13.
} 
Ahora bien, si la dependencia del poder temporal respecto del espiritual es total, y si el poder espiritual se extiende a todo, ¿acaso el poder temporal es superfluo? ¿ ¿no basta con un solo poder? ${ }^{8}$. La respuesta de Egidio se apoya en la analogía entre el modo como Dios gobierna el mundo y el modo como el Papa gobierna la Iglesia. En virtud de su omnipotencia, todo lo que Dios puede con la criatura lo puede sin ella: puede calentar sin fuego, enfriar sin agua'. Pero en virtud de su bondad, Dios comunica su dignidad a las criaturas para que éstas - y no solo Él - actúen como causas de las cosas. Por ello, si en virtud de su omnipotencia, Dios puede operar sobre la realidad sin esas causas, en virtud de su bondad co-opera con ellas ${ }^{10}$. Análogamente el Papa puede gobernar toda la Iglesia con su plenitudo potestatis, pero para actuar más adecuadamente y sobre lo mejor de ella, la cogobierna a través del poder temporal y junto con éste ejecuta actos de gobierno que contribuyen a un gobierno más adecuado del poder espiritual sobre los hombres. Por ello es preferible que, además del poder espiritual - que tiene jurisdicción universal -, exista también el poder temporal que está bajo el poder espiritual, es instituido por él y obra por comisión de él para desempeñar una función definida ${ }^{11}$.

Para superar las dificultades resultantes del carácter no superfluo del poder temporal y de la consecuente simultaneidad de jurisdicciones ejercidas por ambos poderes sobre el mismo ámbito, podemos recurrir a la distinción entre modo de ejercer del poder y esencia del poder. La tesis que concierne al modo de ejercicio del poder dice que ambos poderes son ejercidos simultáneamente y que el poder temporal no es superfluo, sino que tiene jurisdicción legítima pues es instituido por el poder espiritual para facilitar la dedicación del poder espiritual a gobernar las mejores cosas y así optimizar el ejercicio del poder espiritual. Esa tesis no afecta la tesis sobre la esencia de esos poderes, según la cual el poder espiritual puede producir, sin el poder temporal, los mismos efectos que produce con la mediación del poder temporal. Egidio descarta que el poder espiritual pueda con el temporal algo que no podría sin él. Si así fuera, habría en los poderes inferiores un poder que no está en el poder superior ${ }^{12}$ y ello atentaría contra la plenipotencia del poder espiritual, garantizada por el axioma de la entrega de ambos poderes al Papa ${ }^{13}$.

La distinción entre modo y esencia del poder crea un espacio de coejercicio simultáneo de ambos poderes. Este espacio optimiza el modo del ejercicio del poder espiritual mediante el temporal y, al mismo tiempo, conserva intacta la esencia del poder espiritual que permanece intacto y es el mismo tanto en el modo de ejercicio inmediato como en el modo de ejercicio mediato del poder espiritual, que no es un modo esencial o necesario de ejercicio del poder, sino solo más conveniente (decens) ${ }^{14}$. Ello se resume en dos tesis. (a): todo lo que el poder espiritual puede con el temporal, lo puede sin él; esta tesis presenta una situación ontológicamente irrevocable que concierne a la naturaleza ontológica de los poderes y a su mutua relación; esta relación no puede sufrir mutaciones que afecten la plenitudo potestatis del poder espiritual. (b): la existencia del poder temporal como potestas no superflua se justifica porque él puede hacer en la realidad, de otro modo, lo que el poder espiritual puede hacer sobre la misma realidad directamente; esta tesis presenta una situación referida al modo accidental de ejercicio de los poderes, acerca de cuya esencia

\footnotetext{
8 "... quia cum potestas spiritualis extendat se ad omnia et iudicet omnia, non solum animas, sed eciam corpora et res exteriores, videtur, quod unus solus gladius sufficiat" (p. 112)

9 “ ... quicquid potest Deus cum creatura, potest sine creatura ... posset enim Deus calefacere sine igne, infrigidare sine aqua ..." (p. 131).

10 “... voluit dignitatem suam communicare creaturis, et voluit, quod creature sue haberent acciones proprias et virtutes proprias et essent cause rerum...” (p. 131).

11 "Potestas ... terrena est sub spirituali et instituta per spiritualem et agit ex institucione spiritualis potestatis" (p. 114)

12 “... quia aliqua potestas potest esse in inferioribus que non est in superioribus ...” (p. 135).

13 “... utrumque gladium habet ecclesia et utramque potestatem, sibique simul terreni et celestis iura imperii sunt commissa ..." (p. 135).

14 “... non est decens quod [Ecclesia] habeat eam [i.e. execucionem materialis gladii] immediatam” (p. 135).
} 
e inalterabilidad se expide la tesis (a). Egidio presenta la tesis (b) (coejercicio de ambos poderes) como compatible con la tesis (a) (el poder espiritual puede todo con y sin el poder temporal). Esa compatibilidad solo implica la conveniencia de (b) y concierne solo al modo de ejercicio del poder; por ello la tesis (b) es accidental. Egidio presenta la conveniencia expresada por la tesis (b) como situación normal de gobierno: a pesar de su carácter no necesario y accidental, es conveniente (decens) que en situaciones normales coactúen ambos poderes, pero este coejercicio es solo un modo de gobierno que no afecta la esencia del poder cuya naturaleza es expresada por la tesis (a). El coejercicio de ambos poderes en situaciones de normalidad es una regla modal y posible de ejercicio del poder, no una regla esencial o necesaria. Por ello la regla modal (b) puede ser alterada por la regla esencial concerniente al poder mismo y enunciada por la tesis (a).

Para tipificar teóricamente la plenitudo potestatis Egidio vincula la tesis (b) con la tesis (a). La vinculación dice que la tesis (b) que expresa la situación de normalidad en la que cogobiernan ambos poderes puede ser alterada por la situación (a) que expresa el caso de excepción y que tiene lugar cuando el Papa interviene en el orden temporal, no directamente, sino mediante los poderes por él instituidos para casos normales. De esa vinculación resulta que la tesis (a) equivale a la actualización fáctica del ejercicio del poder total por el poder espiritual; esta intervención inmediata se llama casus imminens ${ }^{15} \mathrm{y}$ tiene lugar cuando lo espiritual implicado en lo temporal es afectado por el mal gobierno del poder temporal. En este caso se produce una usurpación de las cosas temporales que pueden ser llamadas espirituales ${ }^{16}$ y pasan a estar bajo la jurisdicción inmediata del poder espiritual ${ }^{17}$. Así, según la tesis (b) el Papa gobierna la Iglesia siguiendo la ley común, actúa uniformemente frente a cada uno de sus miembros ${ }^{18}$, conserva a cada uno en su estado, no impide el oficio de ninguno ${ }^{19}$ y no interviene directamente en los asuntos temporales que corresponden al poder temporal ${ }^{20}$. Pero el Papa puede intervenir in temporalibus si en lo temporal acontece algo que exige su intervención directa ${ }^{21}$. Esta intervención implica -como sucede cuando Dios interviene más allá de la ley natural -, actuar más allá del normal curso de los acontecimientos. Pues, aunque regularmente el Papa gobierna la Iglesia respetando instituciones y leyes que él instituye $\mathrm{e}^{22}$, en casus imminens tiene plenitud de poder para actuar directamente en ella prescindiendo de sus instituciones ${ }^{23}$, pues en virtud de una deficiencia en el ejercicio de los poderes delegados, éstos son reconducidos a su origen hasta que el Papa instituye un nuevo orden institucional en la Iglesia.

El casus imminens equivale al tránsito desde el ejercicio normal del poder mediate hacia su ejercicio pleno immediate, i.e. cuando irrumpe in re todo el contenido conceptual de la tesis esencial (a) que neutraliza

\footnotetext{
15 "Nam quia spiritualis gladius est tam excellens et tam excellentia sunt sibi commissa, ut liberius possit eis vacare, adiunctus est sibi secundus gladius, ex cuius adiunccione in nullo diminuta est eius iurisdictio et plenitudo potestatis ipsius sed ad quandam decenciam hoc est factum, ut qui ordinatur ad magna, nisi casus immineat, non se intromittat per se ipsum et immediate de parvis" (pp. 145 s.).

16 "In hiis ergo casibus ipsa temporalia possunt dici spiritualia” (p. 180).

17 “... in certis casibus, quia ipsa temporalia secundum se et immediate ordinantur ad corpus ... ex mandato tamen domini [spectat ad potestatem ecclesiasticam excercere temporalem iurisdiccionem]” (p. 179).

18 "Sicut ... censendum est de Deo, prout secundum legem communem gubernat totum mundum, sic eciam censendum est de vicario Dei, prout secundum communem legem totam ecclesiam gubernat...” (p. 152).

19 “...summus pontifex... secundum legem communem gubernat ecclesiam et ad omnia uniformiter se habet, quia omnia in suo statu conservat ... nullum in suo officio impedit ...” (p. 155).

20 “Secundum ... legem communem non intromittet se Papa de temporalibus ...” (p. 156).

21 “..nisi aliud speciale in talibus [rebus temporalibus] occurrat...” (ibid.).

22 “... summus pontifex ... secundum has leges debet ecclesiam gubernare ... Ex causa tamen racionabili potest preter istas communes leges sine aliis agentibus agere, quia posse omnium agencium reservatur in ipso, ut sit in ipso omne posse omnium agencium in ecclesia et ut ex hoc dicatur, quod in eo potestatis residet plenitudo" (p. 192).

23 "Posset enim [summus pontifex] providere cuicumque ecclesie sine eleccione capituli, quod faciendo ageret non secundum leges communes inditas, sed secundum plenitudinem potestatis” (p. 191).
} 
provisoriamente la vigencia del contenido conceptual de la tesis modal (b). En el casus imminens el contenido conceptual del posse omnia propio del poder espiritual coincide con el ejercicio concreto de ese posse omnia, i.e. se pone de manifiesto fácticamente la totalidad de ese posse omnia y eclosiona en la realidad toda la potencia de la plenitudo potestatis papal. Como comportamiento del poder originario respecto de los poderes derivados, el casus imminens es una situación extrema que pone a prueba la condición ontológica de esos poderes derivados y les compele a mostrarse en su verdadera naturaleza, aún oculta en el modo de subordinación mediato. Pues el casus imminens desoculta la realidad político-eclesiástica y muestra lo que ella en verdad es: la plenitudo potestatis papal. Ello permite percibir la paradoja que subyace en la estructura del tratado: mientras normalidad y regularidad propias del orden jurídico-institucional de la Iglesia expresan un orden derivado, alterable y accidental, el casus imminens muestra una potestas plena, inalterable y ontológicamente irrevocable.

\section{La teología política de Carl Schmitt como intento de recuperación de la politicidad}

Objetivo del pensamiento de C. Schmitt es recuperar la especificidad de la política. Núcleo conceptual de su pensamiento es lo que ha sido denominado, con razón, la autonomía de la política ${ }^{24}$. Decidido enemigo de posiciones que hacen de la política un epifenómeno de la economía, el derecho o la sociología, Schmitt quiere mostrar que la política no se reduce a otras disciplinas, sino que tiene una esencia propia que permite explicarla desde sí misma. Pero aunque Schmitt combate en todos los frentes que muestran la posible emergencia de una instancia no política con aspiraciones a colocarse por encima de ella para operar como su fundamento, su pensamiento se muestra en todo su apogeo cuando enfrenta a su gran adversario: el normativismo jurídico.

Para superar la simple decisión y privilegiar la norma sobre el arbitrio de la decisión, el normativismo hace de toda norma una derivación a partir de una norma anterior. Pero de ese modo, reprocha Schmitt, el sistema de normas se constituye en un límite permanente más allá del cual es imposible remontarse y del cual es imposible salir. Ello hace del sistema normativo un ab-solutus habilitado para regular todos los conflictos que emergen dentro del orden político. Con ello lo político es subsumido en lo jurídico yéste se transforma en fundamento de lo político. Schmitt identifica el normativismo con el principal protagonista de la despolitización porque hace de la norma un soberano último capaz de resolver las crisis políticas dentro de un marco exclusivamente jurídico. Pero en rigor debería suceder exactamente lo contrario, pues lo político es "... lo que no se puede subsumir" ${ }^{25}$; es excepcional y "escapa a toda determinación general"26.

Schmitt recurre a una situación extrema para oponerse a la despolitización consecuente a la absolutización de la norma: la irrupción de la crisis o del caos del sistema regulado por las normas. Schmitt utiliza la crisis como momento que pone a prueba al sistema de normas. En cuanto situación extrema, la crisis muestra que ésta no se puede resolver con el mismo sistema de normas que fue víctima de la crisis y del caos, pues ello equivaldría a intentar resolver el caos con el caos, la crisis con la crisis, el desorden con el desorden. De allí que las normas en crisis no puedan resolver la crisis de las normas. Más aún, del mismo modo como en situaciones de crisis el derecho no genera derecho, sino que incrementa la crisis del derecho, así las situaciones de crisis muestran que la suspensión del sistema de normas, i.e. la excepción, no se deja

\footnotetext{
${ }^{24}$ Distintas perspectivas acerca de esa autonomía fueron reunidas en el volumen Die Autonomie des Politischen. Carl Schmitts Kampf um einen beschädigten Begriff (Herausgegeben von Hans-Georg Flickinger), Weinheim, VCH, 1990.

${ }^{25}$ En lo sucesivo cito la siguiente edición: Politische Theologie. Vier Kapitel zur Lehre von der Souveränität, Duncker\&Humblot, München-Leipzig, ${ }^{2} 1934$. Aquí, p. 19.

${ }^{26}$ Ibid.
} 
subsumir por una norma: "No existe una sola norma - escribe Schmitt - que se pueda aplicar a un caos"27. Para restablecer el sistema de normas no basta el mismo sistema afectado por las consecuencias del caos.

Si la posibilidad de restablecer el orden jurídico escapa a ese mismo sistema de normas que caduca, esa posibilidad solo se habilita saliendo del sistema de normas en crisis. El restablecimiento del orden no puede lograrse mediante el recurso a las normas en crisis, sino apelando a una instancia ajena a las normas implicadas en la trama de la crisis. En otros términos, el caos exige la irrupción de una instancia no caótica, libre y exceptuada de las consecuencias de la crisis. Schmitt identifica esa instancia no caótica con una decisión que no es normativa y que proviene de una voluntad soberana no jurídica. Esta voluntad soberana extrajurídica y extranormativa opera como límite último más allá del cual es imposible remontarse. Mientras el normativismo está siempre dispuesto a suplir la caducidad de una norma con una norma anterior, el decisionismo, en cambio, sugiere interrumpir drásticamente esa suplencia y sustituir la caducidad de las normas con una decisión que opera como medida última del orden normativo, más allá de la cual es imposible avanzar. Así, mientras el límite del normativismo es siempre el recurso al sistema de normas, el límite del decisionismo es cualitativamente diferente de la norma, ese límite es la decisión política que irrumpe en el momento de crisis.

La crisis neutraliza la vigencia la soberanía de la norma y habilita a un nuevo soberano, el único que puede restaurar el orden jurídico en crisis. Esa decisión no se deduce de una norma ni de un orden previo. Al contrario, la norma y el derecho existen porque son creados por la voluntad y la decisión de una autoridad política. La norma carece de autoridad si no proviene de una decisión: "Como todo orden, el orden jurídico descansa en una decisión, no en una norma"28. Solo la decisión la convierte en norma y solo la decisión constituye el nuevo límite que, por encima del sistema normativo, decide su caducidad y su vigencia.

Ese límite no jurídico constituye la única posibilidad de moderar el caos y de restituir el orden jurídico, pues al tiempo que el caos es desorden y éste es impotente para restaurar la normalidad, la decisión soberana extrajurídica es un posse, una voluntad que en sí misma aún no es orden, pero que tiene la potencia suficiente para introducir un orden y así poner fin a la excepción y suspensión del sistema jurídico producidas por el caos. En la medida en que el orden jurídico resulta de una voluntad, ese orden toma su origen en un acto no jurídico o prejurídico extra-ordinario, i.e. en un acto proveniente de un ámbito no ordinariamente jurídico. Este acto extra-ordinario es esencialmente político, se llama decisión, y es ejercido por una voluntad soberana.

La voluntad soberana suspende la ciega cadena causal del caos del sistema de normas e introduce un sistema normativo con una nueva causalidad, i.e. decide sobre el estado de excepción y de crisis del sistema normas e introduce la vigencia de un orden nuevo. Schmitt define así esa voluntad soberana: "Soberano es el que decide sobre el caso de excepción" ${ }^{29}$. Con su brevedad y concisión, esta definición sintetiza la relación entre las dos instancias más importantes que diseñan el arco dentro del que se desenvuelve el sistema de Schmitt: por un lado la política, que equivale a la decisión soberana, por el otro el orden normativo suspendido, que equivale al caso de excepción.

Aunque Schmitt es escéptico respecto de la posibilidad de que la norma víctima de la crisis resuelva la crisis del sistema normativo y de que esa misma norma en crisis pueda restablecer el orden jurídico en estado de caducidad, no es escéptico respecto de la conveniencia de que rija el sistema de normas. Por ello no privilegia la caducidad del orden jurídico en términos absolutos, sino que se limita a privilegiar su

\footnotetext{
${ }^{27}$ Politische Theologie, p. 20.

${ }^{28}$ Politische Theologie, p. 16.

${ }^{29}$ Politische Theologie, p. 11.
} 
caducidad solamente cuando ese orden entra en crisis. En rigor, prefiere la vigencia de la norma y sostiene que cuando irrumpe el caos del sistema jurídico es necesario restaurarlo para volver a la normalidad. Normalidad significa que el derecho y el orden jurídico vuelven a tener validez: "Es necesario restablecer el orden para que el orden jurídico adquiera sentido. Hay que crear una situación de normalidad...”30.

Aunque, en el orden de fundamentación, la decisión política está por encima de la norma, y aunque en ese mismo orden de fundamentación la voluntad decisoria es siempre superior y está por encima del orden normativo porque es su causa, con todo, en términos absolutos, esa politicidad no es preferible a la norma, ella solo es superior a la norma. Pues Schmitt sostiene que es conveniente la vigencia del sistema de normas cuando este sistema es orden normativo, y lo considera preferible a la vigencia de la excepción y de la decisión, porque la norma es orden. Por ello, cuando el sistema jurídico caduca a causa del caos, esa preferencia aconseja restaurarlo para volver a la normalidad. Cuando el soberano introduce un nuevo orden normativo queda totalmente satisfecha la conveniencia de que rija la norma.

Pero a pesar de que la vigencia de la norma es más conveniente porque ella es orden, siempre el soberano puede más que la norma porque él introduce el orden. Con la irrupción de la decisión del soberano en el caso de excepción queda, para Schmitt, totalmente recuperada la esencia de la política. La decisión es una acción del poder político que opera como constituyente, utiliza la excepción como instancia para actuar contra la Constitución preexistente, para neutralizarla y para crear una nueva Constitución. Esta acción, que proviene de una facultad ilimitada del soberano (unbegrenzte Befügnis) ${ }^{31}$, es equivalente a una omnipotencia soberana. Ésta es, precisamente la situación en la que el soberano decide en caso de excepción. Esta definición de soberano es esencialmente política y no está limitada por el derecho, pues el criterio para medir el derecho y la normalidad es la decisión política que suspende el derecho y el orden en el caso de excepción e introduce un orden nuevo. Siempre lo político se muestra por encima del derecho. La recuperación de la esencia de la política como fundamento de un orden normativo-jurídico permite percibir que, aunque preferible, este orden es siempre frágil a causa de la fugacidad implícita en su posible caducidad: "La existencia del Estado [=de lo político] muestra una clara superioridad sobre la vigencia de la norma" ${ }^{\prime 2}$.

Esta apretada síntesis del pensamiento de Schmitt nos permite concluir con la identificación de algunas estructuras formales de la operatividad del soberano (ontológicamente superior) y sus mutuas relaciones con el orden normativo (ontológicamente inferior):

1) La irrupción de la potencia y de la eficiencia de la decisión política del soberano es habilitada por la falencia y el déficit de la norma. Sabemos quién es el soberano cuando sabemos quién puede decidir sobre la excepción del sistema de normas en el momento de su caducidad.

2) La política, en sí misma, aún no es orden normativo, sino decisión y voluntad, pero ella sí es toda la posibilidad del orden normativo. Solo cuando esa posibilidad de orden se concreta estamos ante la irrupción de la politicidad. Al mismo tiempo, cuando el orden normativo es restablecido, éste ya no es la política, pues tan pronto como la política restaura el orden, ella se retira y permanece latente, como escondida y retirada, a la espera de una nueva irrupción provocada por alguna futura crisis del orden.

\footnotetext{
${ }^{30}$ Politische Theologie, p. 19.

${ }^{31}$ Politische Theologie, p. 19.

${ }^{32}$ Ibid.
} 
3) Para ser derecho, el derecho requiere de la voluntad y de la decisión no jurídicas de la autoridad política. Pero esta decisión política no requiere del derecho para instituir el derecho. La autoridad política no está afectada o limitada por el derecho, está por encima de él.

4) Aun cuando el derecho caduca, éste - no en cuanto este orden jurídico determinado y concreto, sino en cuanto sistema de orden en general - siempre espera la decisión política para volver a tener vigencia; y cuando el orden normativo o derecho está vigente, la decisión política no desaparece, sino que asume una latencia, un estado de "estar en espera" del momento de crisis para poder mostrarse nuevamente como poder soberano e instancia decisoria.

5) El orden jurídico muestra una manifiesta paradoja. Por una parte, en cuanto es orden, no es voluntad ni política. Por la otra, en cuanto a su origen y a su fundamento, ese orden jurídico muestra cierta politicidad, pues el origen de su existencia está en la decisión política del soberano. Pero también la decisión política es paradojal, pues al tiempo que es voluntad y no orden, sin embargo, en ella se concentra toda la posibilidad de la existencia del orden, pues todo el fundamento y posibilidad de existencia del orden jurídico reside en la decisión.

6) Si bien la voluntad soberana muestra absoluta superioridad sobre el orden jurídico pues puede proceder a su caducidad y a la introducción de un orden nuevo, esa voluntad soberana no es equivalente a una automática caducidad de ese orden. La voluntad soberana solo es equivalente a la posibilidad de restaurarlo. Solo en caso de crisis la voluntad soberana es equivalente a la automática caducidad del orden. La voluntad soberana y su politicidad son causa de la caducidad del sistema jurídico solo cuando éste se muestra caótico, y también son garantía de la restauración del sistema jurídico cuando, como consecuencia del caos, ha caducado su existencia.

7) Aunque en el orden de fundamentación la decisión política está por encima de la norma porque es su causa, y aunque siempre la voluntad decisoria es superior y está por encima del orden y de su caos, esa politicidad no es preferible a la vigencia de la norma. Puesto que la norma es orden, su vigencia es preferible a la vigencia de la excepción y de la decisión. Schmitt privilegia la vigencia del sistema de las normas, no su caducidad. El orden es preferible al caos del orden. Cuando el sistema jurídico caduca a causa del caos, esa preferencia aconseja restaurarlo para volver a la normalidad.

8) Schmitt prefiere la normalidad a la excepción; no se opone a que la norma obligue, sino que prefiere esa obligación. Pero la norma obliga exclusivamente en situaciones de normalidad, i.e. en situaciones de vigencia del sistema de normas. Su confrontación con el normativismo se limita a negar la reducción del sistema de normas a una norma o, en última instancia, a una norma fundamental. Pues la norma fundamental, dice, no se deduce de una norma, sino de una decisión política y soberana. Ésta es obligante en situaciones de excepción. Así, su litigio con el normativismo no afecta la validez del sistema de normas, sino solo el fundamento y el origen de esa validez.

9) Aunque norma y orden jurídico obligan cuando tiene vigencia la normalidad, durante esa vigencia la soberanía de la decisión sigue existiendo en estado latente y reducida a un mínimo (auf ein Minimum). El carácter soberano de la decisión como fundamento absoluto de toda norma solo se pone de manifiesto en su verdadera esencia, i.e. solo transita desde ese estado latente a su estado de total actualidad y con irrupción plena en el momento de la excepción, suspensión y crisis del sistema normativo ${ }^{33}$.

\footnotetext{
${ }^{33}$ Politische Theologie, p. 19.
} 


\section{Egidio y Schmitt: semejanzas y diferencias}

“Todos los conceptos sobresalientes de la moderna teoría política son conceptos teológicos secularizados ${ }^{34}$. Esta confesión de parte parece suficiente para relevarnos de alegar pruebas en favor de la fuerte impronta teológica de la teoría política de Schmitt. Con todo, y como conclusión, algunas semejanzas y diferencias entre Schmitt y Egidio nos permitirán marcar con mayor precisión sus respectivas posiciones teológicopolíticas.

En lo que concierne a las semejanzas - siempre teniendo en cuenta que esas semejanzas deben ser entendidas aquí en términos simplemente estructurales y como concernientes solamente a la operatividad del soberano entendido como poder político absoluto - cuatro son las tesis principales de Schmitt que encuentran un antecedente en Egidio:

(1) la excepción y/o suspensión de la vigencia de la normalidad jurídica puede ser estructuralmente analogada al milagro en teología ${ }^{35}$;

(2) es soberano (ab-solutus) quien decide en caso de excepción ${ }^{36}$;

(3) en caso de excepción la decisión política del soberano es análoga a la decisión infalible del Papa ${ }^{37}$; así como el soberano decide sobre el estado de excepción operando desde fuera de ese orden, del mismo modo el Papa decide sobre la crisis de la Iglesia desde fuera y por encima del orden institucional de la Iglesia.

(4) la peculiaridad de la cuarta semejanza es casi ineludible; ella constituye una de las paradojas más interesantes y, al mismo tiempo, de más difícil resolución teórica en ambas teologías políticas. Ella puede formularse así: mientras la normalidad y la regularidad propia del orden jurídico en Schmitt y del orden institucional de la Iglesia en Egidio expresan un orden alterable y accidental, la irrupción del casus imminens en Egidio y del caso de excepción en Schmitt muestran una potestas inalterable y ontológicamente irrevocable. Ello hace del papa en la Iglesia y del soberano schmittiano dos figuras estrechamente asociadas con el momento de la excepción, y ello hace del momento de la excepción el momento en que se pone de manifiesto la esencialidad e inalterabilidad del poder político absoluto.

En cuanto a las diferencias,

(1) La primera se verifica entre el carácter no-secular de la teología política de Egidio y el carácter secular de la teología política de Schmitt. Para Egidio la teoría política depende totalmente de una teología que deja ingresar en la realidad una sacralidad objetiva, extensiva a todo el orden político y que hace de él un orden sagrado. Esta sacralidad no es estructural o formal, sino esencial y constitutiva, y lo es hasta el punto de que cada momento de la política equivale a un momento de la presencia del orden sagrado en el mundo. Pues Egidio sostiene una total sacralización eclesiástica de la política que no admite ni secularización ni emancipación de los momentos políticos de la realidad respecto de la Iglesia; ello permite definir su teoría política como continuación de la teología. En cambio, para Schmitt la presencia de la teología en la política es un "como si". La política, vaciada de sacralidad objetiva, recibe de la teología solo estructuras cuya validez está condicionada por su estricta formalidad. Por ello la teología política de Schmitt es una

\footnotetext{
${ }^{34}$ Politische Theologie, p. 49.

${ }^{35}$ Politische Theologie, p. 49.

${ }^{36}$ ut supra, nota 29.

${ }^{37}$ Politische Theologie, p. 71.
} 
formalización de la teología que no ofrece contenidos a la teoría política, sino estructuras, tipos de relaciones entre sus protagonistas y tipos de operaciones entre ellos solo análogas a las de la teología.

(2) La segunda - y gran - diferencia tiene lugar entre dos decisiones irrevocables: la decisión papal y la del soberano. Puesto que en Egidio la teología equivale a un contenido objetivo que incluye un conjunto de tesis dogmáticas, el papa es infalible porque sabe, i.e. su decisión depende de su conocimiento de verdades objetivas y de existencia real de las que él es el primer e inmediato recipiendario y, consecuentemente, el árbitro último acerca de su contenido, pues él, primero después de Dios en la tierra, actúa veritate testante ${ }^{38}$, es decir, como testigo de una verdad anterior a la decisión y, por ello, determinante de la decisión. En cambio, el soberano de Schmitt es el último árbitro acerca del estado de excepción, pero no porque sabe, sino porque puede decidir acerca de él; en este caso el soberano no opera como testigo y conocedor de la verdad (veritate testante), sino en virtud del poder de su voluntad (voluntate potente). Con ello, la diferencia entre ambos está marcada por el conocimiento que según Egidio define la infalibilidad papal acerca del contenido del Cristianismo y por la voluntad del soberano que según Schmitt define su infalibilidad porque el poder de esa voluntad lo muestra colocado por encima de cualquier otra voluntad decisoria.

(3) Si en el caso de la segunda diferencia la decisión papal parece ganar una cierta objetividad en comparación con la decisión política del soberano cuyo arbitrio se apoya solo en su voluntad, en cambio en esta tercera diferencia puede señalarse una suerte de pérdida de racionalidad en la decisión infalible del papado, pues mientras éste recurre a un conocimiento objetivo revelado, en el caso de Schmitt la decisión apela a un principio de indiscutida racionalidad "instrumental", que es la necesidad de restablecer un orden que garantice el retorno a la norma.

\section{Conclusión}

Mi problema aquí no fue fundamentar la existencia de un absoluto político ni definir su condición ontológica. Tampoco fue justificar su operatividad, pues si admitimos que ese absoluto político existe, debemos admitir que él opera de modo consecuente con su carácter ab-solutus. Mi problema consistió en esclarecer en qué medida naturalismo y/o voluntarismo están comprometidos en la respuesta de la teología política a la pregunta por el origen del orden político. En otros términos, intenté encontrar el fundamento último de dos decisiones que se presentan como últimas e irrevocables desde fuera de sí mismas al momento de instituir un orden político. Egidio presenta la decisión soberana del Papa como última porque es infalible, mientras que Schmitt presenta la decisión política soberana como última porque es la única que puede. ¿Podemos agregar algo más a cada una de esas dos decisiones últimas?

Podemos encontrar ese algo más y específico de cada decisión analizando la segunda diferencia - señalada más arriba - entre la decisión papal en Egidio y la decisión soberana Schmit. De esa diferencia resultaba que, en Egidio, la teología es portadora de un conjunto de verdades objetivas que el papa conoce y de las que él es el intérprete. La decisión papal es un acto infalible porque el papa es el primer e inmediato recipiendario de ellas porque su decisión depende de su conocimiento de esas verdades de cuyo contenido él es el árbitro último. El papa opera veritate testante, es decir, como testigo de una verdad determinante de la decisión porque es anterior a ella. En cambio, el soberano de Schmitt es el último árbitro acerca del estado de excepción, pero no porque sabe, sino porque puede decidir acerca de él; en este caso el soberano no opera veritate testante, sino voluntate potente, aunque, como lo he señalado, asistido por una buena dosis de racionalidad "instrumental" implícita en la necesidad de corregir el caos y restablecer un orden que garantice el retorno a la norma.

\footnotetext{
${ }^{38}$ La expresión es de la Bula Unam Sanctam, en Corpus Iuris Canonici (Extravv. commun., lib. I., tit. VIII, "De maioritate et obedientia”, cap. I), ed. Friedberg, vol. II, 1246.
} 
En síntesis, aunque en Schmitt y Egidio decisión soberana e infalibilidad papal son irreductibles a una instancia precedente y aunque ambas decisiones están colocadas por encima de cualquier otra decisión, existe una relevante diferencia entre nuestros dos "teólogos" de la política: según Egidio, el papa tiene un conocimiento del contenido del Cristianismo que hace de la decisión papal una decisión infalible; y según Schmitt, la voluntad soberana define su infalibilidad en virtud de la racionalidad implícita en la posibilidad del soberano de restaurar el orden jurídico considerado, no como este orden, sino como orden en general. Ambos suscribirían a Horacio: "hay una medida en las cosas, hay ciertos límites más allá de los cuales no puede consistir lo recto"39.

\section{Referencias bibliográficas:}

Bula Unam Sanctam. In: Corpus Iuris Canonici (Extravv. commun., lib. I., tit. VIII, "De maioritate et obedientia”, cap. I), ed. Friedberg, vol. II, 1246.

Carrasco, M. P., "El giro hacia la descolonizaciòn del pasado en la historiografia medieval”. In: Patristica et Mediaevalia XXXVII (2016), pp. 37-50.

DE LAGARDE, G. La naissance de l'esprit laïque au déclin du moyen âge. T. I : Bilan du XIII' siècle. T. II: Marsile de Padoue ou le premier théoricien de l'État laique, Saint-Paul-Trois-Châteaux, éditions Béatrice, 1934 (con sucesivas reediciones).

Egidio Romano, Aegidius Romanus. De ecclesiastica potestate. Edición de R. Scholz. Scientia, Aalen, 1961.

Flickinger, H.-G. (Her.), Die Autonomie des Politischen. Carl Schmitts Kampf um einen beschädigten Begriff (Herausgegeben von Hans-Georg Flickinger), Weinheim, VCH, 1990.

PIAIA, G., "Storia della filosofia e decolonizzazione del passato". In: idem, Il lavoro storico-filosofico. Questioni di metodo ed esiti didattici, Padova, 2007, pp. 11-30 (originalmente publicado en Storiografia ed ermeneutica. Atti del XIX Convegno di assistenti universitari di filosofia, Padova, Gregoriana, 1974, pp. 47-60).

Scattola, M. Teología política, Nueva Visión, Bs. As., 2008.

Sснмiт, C., Politische Theologie. Vier Kapitel zur Lehre von der Souveränität, Duncker \& Humblot, München-Leipzig, 1934, $2^{\text {a }}$ ed.

Recebido em 01 de julho de 2020. Aceito em 20 de fevereiro de 2021.

\footnotetext{
${ }^{39}$ Est modus in rebus, sunt certi denique fines, quos ultra nequit consistere rectum (Horacio, Sátiras, I, i, 106-7).
} 